\title{
РОЛЬ ЦИФРОВОЙ ЭКОНОМИКИ В РАЗВИТИИ ВНЕШНЕЙ ТОРГОВЛИ РЕСПУБЛИКИ БЕЛАРУСЬ
}

\author{
А.Г. Галова
}

Анализируются основные направления цифровой трансформации белорусской экономики. Особое внимание уделено счету текущих операций Платежного баланса Республики Беларусь. Выделены позиции, необходимость изменения которых в контексте цифровой экономики является актуальной в настоящее время: развитие платежно-расчетного пространства, ИТ-услуг, транспортных услуг и логистики. Рассматриваются направления, позволяющие улучшить основные макроэкономические показатели.

Ключевые слова: цифровая экономика, информационно-коммуникационные технологии, платежный баланс, счет текущих операций, экспорт, импорт, сальдо, ИТ-услуги.

JEL-классификация: Е01, O33, P52.

DOI: $10.46782 / 1818-4510-2021-1-130-139$

Материал поступил 21.12.2020 2.

Перспективы экономического развития Республики Беларусь определяются кардинальными инновационными изменениями, к числу которых относятся прежде всего возникновение и развитие цифровой экономики. При обосновании необходимости и основных задач цифровизации экономики в нашей стране следует исходить из общемировых тенденций в данной области и из особенностей, проблем и возможностей собственно белорусской экономики.

\section{Роль цифровизации в развитии мировой әкономики}

Термин «цифровая экономика» появился в 1995 г. и быстро получил распространение, заменив такие понятия, как: «Web Economy», «Internet Economy», «Network Economy». Термин «цифровая экономика» приобрел более конкретное содержание. Это экономика, базирующаяся на цифровых компьютерных технологиях, но, в отличие от вышеназванных терминов, цифровая экономика не строится только на внедрении информационных технологий, она принципиальным образом преобразу- ет бизнес-процессы на базе интернета и новых цифровых технологий.

Сначала было принято выделять три составляющих цифровой экономики: инфраструктуру электронного бизнеса (компьютер, сети, софтвер и др.); электронный бизнес, т. е. процессы организации бизнеса с использованием компьютерных сетей; розничные интернет-продажи товаров. Однако по мере распространения новых технологий этот термин приобрел более широкий смысл, в него добавились новые элементы. Под цифровой трансформацией следует понимать не просто очередной этап преобразований в области информационно-коммуникационных технологий (ИКТ), а коренные изменения под влиянием новых ИКТ-продуктов традиционных сфер экономической деятельности. Цифровая экономика предполагает научные и практические разработки в таких областях, как интернет вещей (IoT), «большие данные» (Big Data), облачные вычисления (Cloud Computing), искусственный интеллект (ИИ), которые становятся все более важными в обеспечении перехода к высоко-

* Галова Анна Геннадьевна (roxan963@mail.ru), кандидат экономических наук, доцент, Белорусский государственный университет (г. Минск, Беларусь). 
технологичной экономике, конкурентоспособной на мировом рынке. Цифровая экономика имеет огромный потенциал для бизнеса, создания рабочих мест, новых драйверов развития страны. Страны, которые связывают свое будущее с цифровой экономикой и уделяют ее вопросам значительное внимание (например, Китай), считают, что уже через 2-3 года цифровая экономика составит более половины их ВВП 1 .

В соответствии с существующим способом определения размеров цифровой составляющей экономики удельный вес информационно-коммуникационных технологий (ИКТ) в валовой добавленной стоимости в нашей стране в 2019 г. составил 5,6\%. В таких странах, как Китай, Япония, Южная Корея, он достигал 8-10\% еще в 2017 г. Однако этот подход к оценке является ограниченным, поскольку не учитывает дополнительный вклад, который цифровизация вносит в развитие традиционных и новых секторов экономики. И здесь правильнее было бы применить методологию оценки, позволяющую определять результаты и роль цифровой экономики в общих результатах экономического развития страны. Такая оценка могла бы быть проведена на основе использования таблиц «затратывыпуск». В этом случае долю цифровой экономики Китая, например, в том же году можно определить уже как 33\% ВВП (Елохов, Александрова, 2019).

Дополнительное ускорение процессы цифровизации приобрели за последний год в связи с пандемией короновируса и локдауном (введением строгих ограничений на поездки, коммуникации и доступ к общественным пространствам). Это коренным образом изменило торговые и социальные взаимодействия, появилась необходимость в создании дополнительных программ для организации коммуникаций и контроля за работающими дистанционно. Стремительно происходит смещение потребления в онлайн-сегмент, стали развиваться системы интернет-доставки товаров, оказания и оплаты услуг в онлайн-режиме. По оценке экспертов, эти тренды в значительной сте-

${ }^{1}$ China's digital economy on the rise: new engine, new opportunities. URL: http://xinhuanet.com/english/2018-03/ 01/c_137009083.htm пени сохранятся и в будущем, что делает задачу развития цифровых рынков еще более актуальной.

Таким образом, в настоящее время сформировался новый потенциал модернизации и инновационного развития экономики. Доступность, простота использования и низкая стоимость мобильных коммуникаций привели к быстрому росту объемов трансграничных потоков информации, а рынки развивающихся стран приобрели значительный потенциал для роста производства услуг с высокой интеллектуальной составляющей. Конкуренция будет нарастать, а ее перспективы - зависеть не только от взаимодействия рыночных сил, но и от качества государственной политики в отдельных странах. Особую роль выполняют в этом процессе финансовые технологии (FinTech) - отрасль, использующая технологии и инновации и конкурирующая с традиционными финансовыми организациями в лице банков и посредников на рынке финансовых услуг. Серьезным толчком для дальнейших значимых преобразований в рассматриваемой области может стать внедрение цифровой валюты центральных банков (central bank digital currency, CBDC). Такие проекты активно реализуются уже во многих странах. Так, в мае 2020 г. Народный банк Китая в рамках пилотной программы ввел в четырех регионах страны национальные цифровые деньги, появилась возможность совершать расчеты в цифровых юанях. О возможном выпуске цифровой валюты в октябре 2020 г. объявили Европейский центральный банк, Банк России и ряд других центральных банков. Цифровые валюты являются принципиально новым проектом, способным вызвать очередной виток технологических изменений и стать основой для появления дополнительных цифровых финансовых инструментов и механизмов их функционирования. Цифровые валюты центральных банков не имеют основного недостатка криптовалют - отсутствие субъекта универсальных безусловных финансовых обязательств, эмитента - таковым остается государство. В то же время авторы проектов говорят о них как о новой, третьей форме денег, наряду с существующими наличны- 
ми и безналичными ${ }^{2}$. Развитие цифровых технологий и появление цифровых платформ, услугами которых могут пользоваться десятки и сотни миллионов пользователей, принципиально меняют структуру финансовых систем и даже саму природу денег. Сама по себе цифровизация денег не является чем-то в принципе новым. Например, банковские счета и расчеты с помощью цифровых денег уже существуют в электронной форме. Но новые цифровые валюты должны стать основой крупных технологических платформ, которые выходят за пределы национальных границ, и появление таких денег может изменить структуру международной валютной системы, особенности валютной конкуренции и роль денег, выпускаемых государствами.

\section{Цифровизация в Беларуси}

Применительно к Республике Беларусь необходимость ускоренного развития цифровых технологий становится особенно актуальной на фоне ее вовлеченности в мировую экономическую систему, серьезного влияния интеграционных процессов и острой необходимости поиска новых источников экономического роста. Внедрение таких технологий должно не просто оказать положительное влияние на экономику, это является практически безальтернативным вариантом для такой страны, как наша. По некоторым показателям развития цифровой экономики Республика Беларусь все еще имеет недостаточно удовлетворительные результаты. Например, по такому индикатору, как скорость мобильного интернета, к середине 2020 г. страна находилась только на 121-м месте ${ }^{3}$. Отставание здесь может затруднять перевод различных сервисов в онлайн-формат. В то же время существуют области экономической деятельности, в которых мы достигли гораздо более значимых результатов. Активно развивается в республике сектор ИКТуслуг. В Национальной стратегии устойчивого социально-экономического развития Республики Беларусь до 2030 года намечено довести долю сектора ИКТ в валовом внут-

2 URL: https://econs.online/articles/ekonomika/ budushchee-deneg-v-tsifrovom-mire/

${ }^{3}$ URL: https://www.speedtest.net/global-index реннем продукте до 6\%, а также добиться вхождения Беларуси в тридцатку ведущих стран мира в рейтинге государств по развитию ИКТ. Достигнуть таких результатов предполагается за счет ускорения разработки программного обеспечения и услуг, широкого использования высокотехнологичного компьютерного и сетевого оборудования, содействия развитию нейронных сетей, интернета вещей, 3D-печати, обработки больших массивов данных, технологий искусственного интеллекта, совершенствования системы подготовки и обеспечения кадрами и механизмов поддержки сферы ИТ-услуг. В качестве главных задач данный документ называет:

развитие мультисервисной сети электросвязи, широкополосного доступа к сети интернет, цифрового эфирного и кабельного телевизионного вещания, сотовой подвижной электросвязи нового поколения, интернета вещей, облачных технологий;

обеспечение правовых, технических и экономических возможностей доступа к современным услугам связи и информационным ресурсам для всех категорий пользователей;

обеспечение прозрачности, безопасности и удобства коммуникаций между гражданами, бизнесом и государством путем их перевода в электронную форму, развития портала электронных услуг, сервиса электронных обращений;

развитие электронных услуг на основе интеграции информационных систем и предоставления доступа к открытым данным; формирование внутреннего спроса на ИТ-услуги за счет широкого внедрения информационно-коммуникационных технологий в производственной и социальной сферах, государственном управлении, обороне; расширение экспорта услуг в сфере информационных технологий и программных продуктов ${ }^{4}$. Разработана и в целом выполняется Стратегия развития цифрового банкинга в Республике Беларусь на 2016-2020 годы ${ }^{5}$, которая определила цели, задачи и основные

${ }^{4}$ Национальная стратегия устойчивого социально-экономического развития Республики Беларусь до 2030 года. URL: http://www.economy.gov.by/uploads/files/NSUR2030/ Natsionalnaja-strategija-ustojchivogo-sotsialno-ekonomicheskogorazvitija-Respubliki-Belarus-na-period-do-2030-goda.pdf ${ }^{5}$ URL: https://www.nbrb.by/ 
направления развития цифрового банкинга. Создаются новые цифровые продукты и услуги, цифровые каналы продаж, повышаются количество и качество финансовых цифровых услуг для населения. Данная область сегодня настолько динамична, что необходимость в новых технологиях, стратегиях, сферах внедрения цифровых технологий актуальна как никогда.

В настоящее время основными направлениями практической реализации элементов цифровой экономики в нашей стране являются развитие платежного и расчетного пространства, систем удаленной идентификации, искусственного интеллекта, машинного обучения и работа с большими данными. К задачам, которые сегодня решаются в рамках этих направлений, относятся такие, как развитие бесконтактных технологий, внедрение международного стандарта ISO в существующие автоматизированные системы, внедрение сервисов, обеспечивающих удобную и эффективную организацию торговли и инициирования платежей, совершенствование дистанционного банковского обслуживания и технологий распределенных реестров. Республика Беларусь стала одной из первых стран, в которой начато практическое применение технологии блокчейна в работе банков. На ее основе:

- разработаны практические задачи по ведению реестров банковских гарантий и операций с ценными бумагами на базе ОАО «БВФБ»;

- создана автоматизированная система по реализации товаров и расчетов по ним;

- реализуется практический проект по внедрению смарт-контрактов;

- решается задача по переводу из документарного обмена в цифровой формат процесса совершения исполнительных надписей нотариусов.

В рамках работы Конфедерации цифрового бизнеса обозначены такие проекты, как цифровая личность, межбанковская и трансграничная платежные системы, торговое финансирование, вторичный рынок долговых обязательств и ценных бумаг. Отмеченные направления развиваются в первую очередь в денежно-кредитной и финансовой облас- тях, что является логичным и соответствует мировым тенденциям.

\section{Результаты внешней торговли как проявление конкурентоспособности әкономики Беларуси}

Помимо общемировых тенденций, определяющих актуальность развития цифровизации, на белорусскую экономику влияют факторы, которые диктуют особую актуальность такого развития для нашей страны и обусловлены собственно ее внутренними причинами и задачами. Эти задачи вытекают из специфики структуры экономики, особенностей внешней торговли и состояния платежного баланса страны. Структура экономики, ее принципиальная импортоемкость, при отсутствии достаточных собственных природных ресурсов для обеспечения имеющегося производства, низкий удельный вес высокотехнологичных производств в структуре промышленности (в 2019 г. доля высокотехнологичных производств в объеме промышленного производства составила всего $2,8 \%)^{6}$ проявляются в многолетнем отрицательном сальдо платежного баланса Республики Беларусь и счета текущих операций в частности (рис. 1). В структуре импорта Республики Беларусь преобладают минеральные продукты $(20 \%)$, машины и оборудование (18\%). Основными товарными позициями нашего импорта являются нефть, газы нефтяные, углероды газообразные, легковые автомобили. Сложности с привлечением иностранных инвестиций также не способствуют

${ }^{6}$ URL: https://goo-gl.ru/6Ay1/

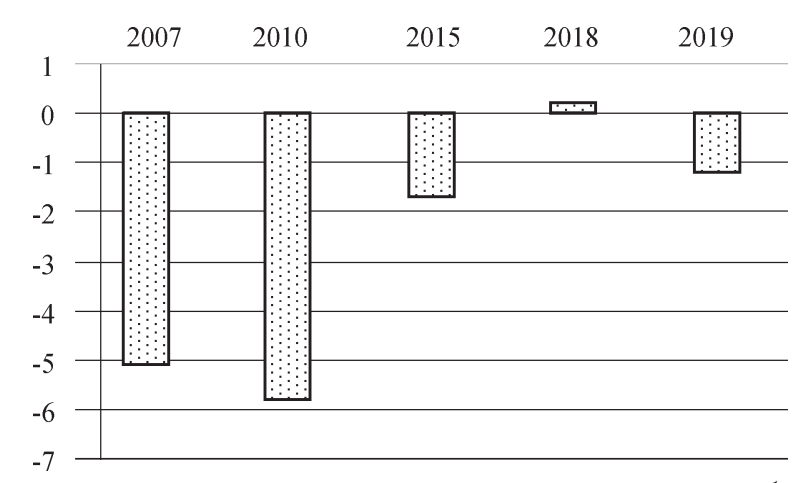

Рис. 1. Сальдо счета текущих операций в Республике Беларусь, 2007-2019 гг., млрд долл. США

Источник. URL: http://www.nbrb.by/publications/ BalPay 
улучшению сбалансированности внешней торговли.

В отдельные периоды, характеризующиеся изменениями внешних условий торговли, баланс счета текущих операций имел определенный профицит, ситуация несколько улучшается в последнее время, однако тенденция к отрицательному сальдо до сих пор носила достаточно устойчивый характер. Выход на положительные значения сальдо баланса может быть связан у нас и с сокращением импорта, что не самым лучшим образом влияет на экономическое развитие страны. К примеру, за 9 месяцев 2020 г. имело место сокращение импорта нефти в два раза и внешнеторгового оборота товаров и услуг на $17,1 \%$. Это, в свою очередь, отражается и на показателях сальдо счета текущих операций ${ }^{7}$

Несбалансированность внешней торговли и платежного баланса создает проблемы на валютном рынке, усиливает действие девальвационных и инфляционных факторов, осложняет задачу поддержания необходимого уровня золотовалютных резервов и внешнего долга. В настоящее время большинство белорусских экономистов согласны в том, что главными направлениями совершенствования экономики страны являются: изменение ее структуры за счет снижения доли материалоемких и энергоемких производств (кото-

7 URL: https://www.nbrb.by/publications/balpay/ balpay2020_3.pdf рые к тому же в значительной степени относятся к IV укладу), возрастание доли высокотехнологичных производств, развитие альтернативных источников энергии, рост внешней торговли услугами.

Особую роль внешней торговли услугами по сравнению с внешней торговлей товарами для нашей страны можно проиллюстрировать данными платежного баланса за последнее десятилетие. На рис. 2 показан различный вклад этих видов внешней торговли в ее общие итоги.

Сальдо внешней торговли услугами на протяжении рассматриваемого периода являлось положительным, и размер его все время возрастал. Сальдо внешней торговли товарами имело в основном отрицательные значения. По данным за 9 месяцев 2020 г. счет текущих операций сложился отрицательным (0,5 млрд долл. США $)^{8}$.

\section{Внешняя торговля услугами в Беларуси}

Таким образом, снизить зависимость от материалоемких и энергоемких производств, влиять на результаты внешней торговли в необходимом для страны направлении в ближайшее время можно и нужно прежде всего за счет роста доли услуг во внешней торговле. Именно стимулирование экспорта услуг является приоритетной задачей совершенствования нашей экономики.

${ }^{8}$ URL: http://www.nbrb.by/publications/BalPay/

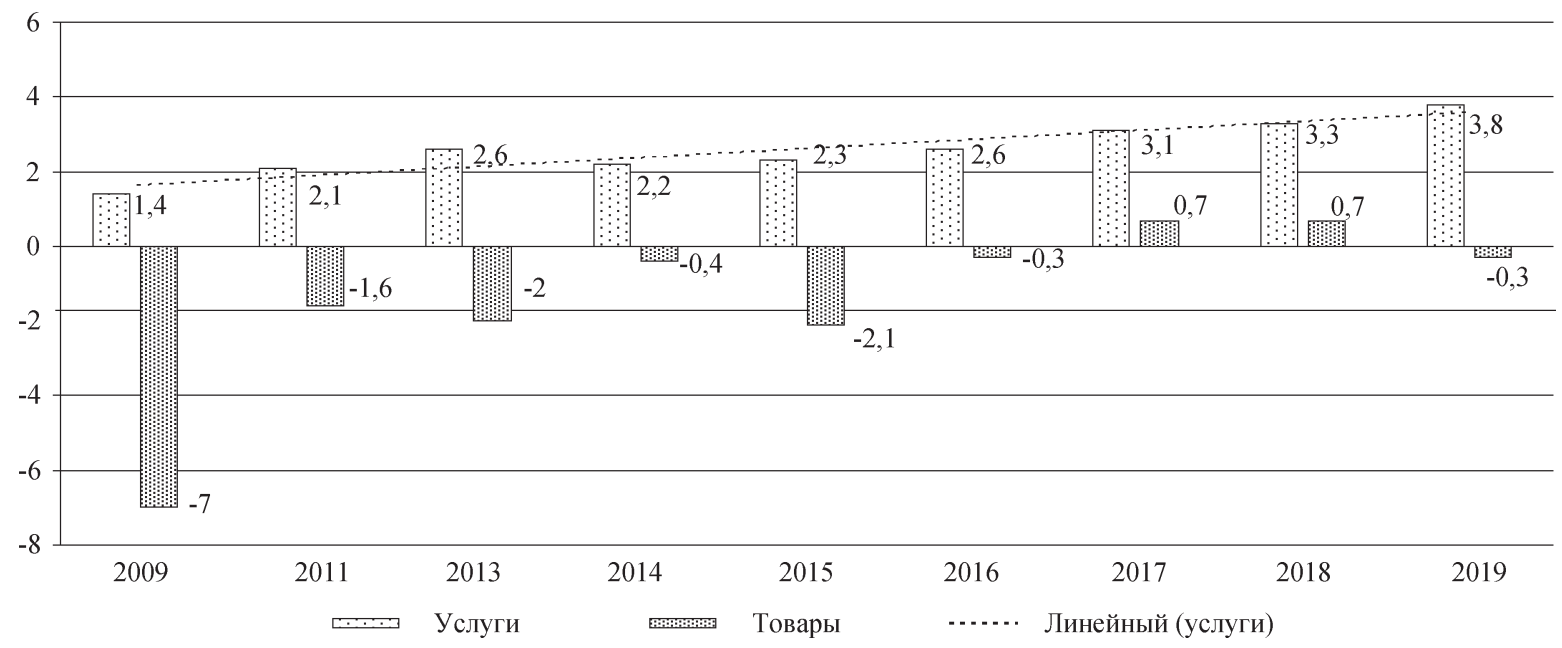

Рис. 2. Сальдо внешней торговли товарами и услугами в Республике Беларусь, 2011-2019 гг., млрд долл. США

Источник. URL: http://www.nbrb.by/publications/BalPay 
На рис. 3 показано сальдо внешней торговли услугами по наиболее значимым в количественном выражении позициям из этой категории. Основной результат в формирование положительных итогов баланса вносят две группы услуг - транспортные (положительное сальдо в размере 2,1 млрд долл. США в 2019 г.) и услуги, объединенные в группу «телекоммуникационные, компьютерные и информационные» (ИТ-услуги) (2,0 млрд долл. США). Поездки, строительные и финансовые услуги вносят отрицательный вклад (229, 332,2 и 182,1 млн долл. США в 2019 г. соответственно).

Высокая доля экспорта транспортных услуг является традиционной для белорусской экономики и связана с конкурентным преимуществом транзитного местоположения и относительно развитой сетью дорог. Доля этой статьи в общем объеме внешней торговли услугами стабильно составляет около 40-44\% в разные годы. К середине 2020 г. абсолютное значение положительного сальдо по телекоммуникационным, компьютерным и информационным услугам впервые превысило значение этого же показателя по транспортным услугам (1,1 и 0,9 млрд долл. США соответственно). По данным за I полугодие 2020 г. услуги, объединенные в группу «телекоммуникационные, компьютерные и информационные», внесли основной вклад в формирование профицита внешней торговли услугами 1,6 млрд долл. США, а транспортные услуги - 1,4 млрд долл. США.

\section{Внешняя торговля ИТ-услугами}

В соответствии с 6-м изданием Руководства по платежному балансу и международной инвестиционной позиции статья «Телекоммуникационные, компьютерные и информационные услуги» состоит из трех основных компонентов. Доля информационных услуг для нашей страны в ней не значима. Соотношение телекоммуникационных и компьютерных услуг постепенно менялось, и в настоящее время более $98 \%$ приходится на компьютерные услуги (10 лет назад их доля составляла около 55\%)

Тенденция повышения роли ИТ-услуг и их доли в структуре платежного баланса соответствует общемировой, однако в Республике Беларусь имеют место намного более высокие темпы ее роста по сравнению с аналогичными показателями в среднем для мировой экономики (рис. 4). По показателю доли экспорта ИТ-услуг в общем экспорте мировых услуг малых европейских стран с открытой экономикой наша страна занимает третью позицию (31,3\%) после Ирландии (более $50 \%$ ) и близка к Финляндии ${ }^{10}$. Ирландия является абсолютным лидером по вкладу в мировой экспорт ИТ-услуг среди европейских стран с малой открытой экономикой и опережает по объемам их экспорта даже такие страны, как США и Китай. Важную роль в этом сыграло правильно выбранное страте-

9 URL: http://www.nbrb.by/publications/BalPay

${ }^{10}$ URL: https://www.wto.org/english/res_e/statis_e/

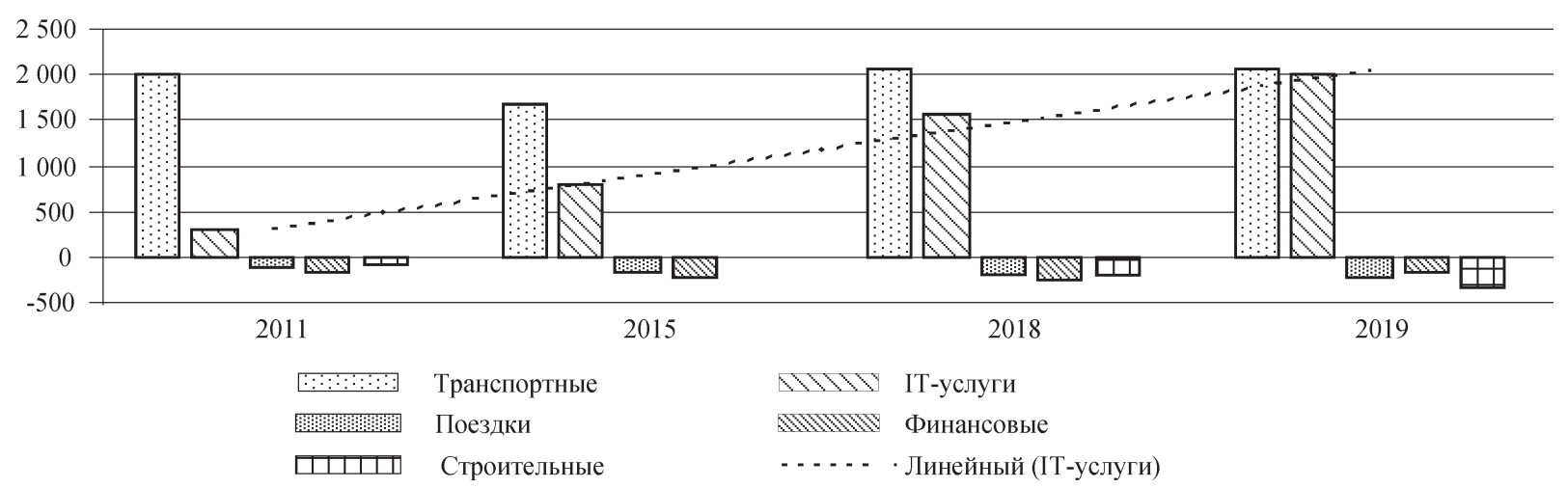

Рис. 3. Сальдо внешней торговли основными услугами в Республике Беларусь, 2011-2019 гг., млн долл. США

Источник. URL: http://www.nbrb.by/publications/BalPay 


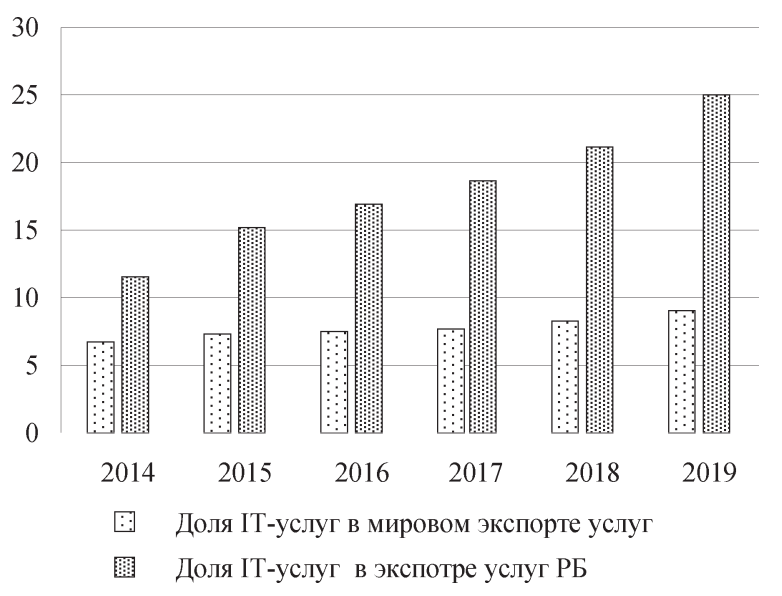

Рис. 4. Доля IT-услуг в экспорте услуг в мире и в Республике Беларусь, 2014-2019 гг., \%

Источник. URL: http://www.nbrb.by/publications/ BalPay/; URL: https://www.wto.org/english/res_e/statis_e/

гическое направление - развитие ИТ-услуг в стране как важнейшего фактора экономического роста, значительные государственные инвестиции в информационные технологии, телекоммуникации. Сегодня европейские штаб-квартиры большинства гигантов, включая Google, Apple, Facebook, Amazon, eBay, PayPal, Yahoo (теперь Oath), Twitter, Accenture, Airbnb и другие компании, расположены в таких районах Дублина, как Кремниевые Доки (Silicon Docks) и Диджитал-хаб (Digital Hub). Это является одновременно и результатом соответствующей экономической политики в стране, и фактором, обеспечивающим ее дальнейшее развитие.

Расширение данного вида услуг в Беларуси можно оценить достаточно высоко даже по абсолютным показателям. По абсолютному объему она входит в 12 европейских государств с малой открытой экономикой с наиболее высоким экспортом ИТ-услуг и в восьмерку этих стран по размерам сальдо ИТуслуг (Столярова, 2020). Необходимо также отметить, что в целом в Центральной и Восточной Европе наблюдается активное вовлечение в экспорт ИТ-услуг - Румыния, Чехия, Венгрия, Сербия и некоторые другие государства являются конкурентами Республики Беларусь в данном направлении. Поэтому от того, насколько успешно будет развиваться сектор ИТ-услуг и их экспорт, зависит международная конкурентоспособность и перспективы экономического развития страны в целом. Беларусь на дан- ный момент имеет уникальную позицию в международной торговле ИТ-услугами, которая является результатом предшествующей деятельности (законодательной, деятельности парка высоких технологий), и ее необходимо сохранить в дальнейшем.

\section{Цифровые технологии в сфере внешней торговли транспортныли услугами}

Необходимость развития цифровых технологий в сфере банковских услуг и внешней торговли ИТ-услугами в принципе не вызывает возражений, и речь идет в основном об ускорении темпов создания и внедрения новых технологий, задаче включения их в приоритеты экономического развития и создания дополнительных условий регулирования для стимулирования их практической реализации.

В то же время подход к проблеме со стороны иных отраслей нашей экономики и стратегия их совершенствования в контексте цифровизации разработаны недостаточно. Учитывая значимость для Республики Беларусь такой отрасли, как транспорт, высокую долю транспортных услуг в платежном балансе и особенности общемировых тенденций в этой области, представляется необходимым определить направления развития цифровой экономики прежде всего применительно именно к этому сегменту, выделить его в качестве приоритетной задачи белорусской экономики. Сегодня перспективы экономического развития республики в немалой степени зависят от ее вовлеченности в процесс международной транспортной интеграции, способной обеспечивать значительные временные и стоимостные выгоды от транзитных перевозок по своей территории. Беларусь оказывает внешнеторговые транспортные услуги в основном за счет услуг железнодорожного и автомобильного (примерно в равной доле), а также трубопроводного и, в меньшей степени, воздушного транспорта (рис. 5).

Наиболее удачным примером применения новых технологий на транспорте и в логистике является опыт Китайской Народной Республики. Именно в этой стране активно продвигаются технологии искусственного интеллекта, используются беспи- 


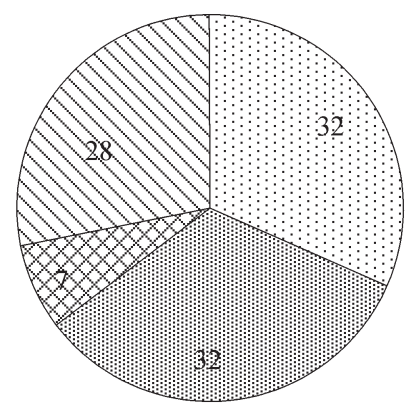

$\begin{array}{llll}0.2 & \text { Железнодорожный } & \text { Автомобильный } \\ \text { Воздушный } & \text { Трубопроводный }\end{array}$

Рис. 5. Структура внешней торговли транспортными услугами в Республике Беларусь по основным видам транспорта, 2020 г., \%

Источник. URL: https://www.nbrb.by/statistics/balpay

лотные автомобили, системы планирования маршрутов, совместимые с такими автомобилями и картами высокого разрешения. Правительство Китая инвестирует в развитие отрасли, в разработки систем искусственного интеллекта и совершенствование алгоритмов для обработки «Больших данных». В этой стране реализуются многочисленные комплексные программы по строительству и модернизации автомобильных дорог и улучшению транспортной инфраструктуры в целом (Сазонов, 2020).

Появление высокоскоростных автомобильных магистралей в Китае стало огромным инновационным прорывом и играет большую роль в области стимулирования экономики. Экстернальные эффекты от расширения высокоскоростной сети вызывают общий прирост макроэкономических показателей (рост ВВП, увеличение доходов бюджета). Они возникают в результате распространения по межотраслевым связям первоначального роста спроса, объемов грузовых и пассажирских перевозок. В свою очередь, это сопровождается увеличением доходов населения, прибыли предприятий, налогов, заработной платы. В итоге растет конечный спрос государственных и частных предприятий, всего населения. Мультимодальные (смешанные) перевозки с применением автомобильного транспорта и с последующим подключением к логистическому процессу других видов транспортного комплекса оказываются более быстры- ми и обеспечивают значительный синергетический эффект в рамках одной логистической цепочки по сравнению с перевозками, осуществляемыми только одним видом транспорта. Активно продвигаются разработки в области автомобильного интернета ${ }^{11}$. Ведется разработка и внедрение стандарта связи $5 \mathrm{G}$, что будет стимулировать развитие интернета вещей, поддерживая взаимодействие и функционирование беспилотных автомобилей, с минимальным вмешательством человека или вообще без его участия. Приложения для беспилотных автомобилей обеспечивают связь автотранспортных средств с окружающей средой посредством их подключения к информационной сети, которая имеет систему управления движением. Внедрение сетей $5 \mathrm{G}$ в Китае планируется осуществить в течение 2020-2022 гг., и многие научные центры в стране активно вовлечены в их создание. В 2019 г. уже созданы два научных центра для разработки системы сотовой передачи данных следующего поколения в формате $6 \mathrm{G}^{12}$.

Китайская Народная Республика, безусловно, является технологическим лидером в области транспортных услуг и логистики, ее достижениям сложно соответствовать. В то же время отсутствие должного внимания к данной проблеме и нарастание отставания в применении цифровых технологий в этой сфере может привести к утрате конкурентных преимуществ нашей экономики и негативно отразиться на результатах экономической деятельности в целом. В настоящее время белорусские специалисты работают над определением перспектив и элементов цифровой логистики, включающей использование технологии интернета вещей в складском хозяйстве, 3D-печати на логистических складах, транспортных беспилотников, системы электронного документооборота и ряда других цифровых сервисов (Королева, 2019). Необходимы организация безбарьерной логистики в международных перевозках, развитие интеллектуальных транзитных коридоров

11 URL: https://www.globaltimes.cn/content/ 1139167.shtml

${ }^{12}$ URL: http://www.china.org.cn/opinion/2019\$08/14/ conte 
с внедрением единого центра управления движением, формирование интеллектуальной транспортной системы, интегрированной с транспортными системами ЕС и ЕАЭС, объединяющей автомобильный, железнодорожный, воздушный и водный транспорт на основе единого информационного транспортного пространства.

Особое внимание в области внешней торговли транспортными услугами и логистики необходимо уделить внедрению новых цифровых технологий в сфере платежей. Существующие способы оплаты при трансграничных перевозках, необходимость конвертации валюты снижают эффективность логистической деятельности, создают дополнительные риски. В настоящее время во многих странах идет создание и экспериментальная проверка инструментов нового типа, которые могут обеспечить быструю систему платежей, стабильность и снижение накопления рисков. Примером таких инструментов являются токенизированные активы (token), они начинают выпускаться и в Беларуси, но пока только для внутреннего пользования. За последние два-три года в мире было создано несколько моделей трансграничных платежей на базе таких платежных инструментов, не связанных с коммерческими банками и ориентирующихся на проекты цифровой валюты центрального банка. Эти модели основаны на децентрализованных технологиях, а поддерживает данные платежи именно центральные банки, что является принципиально новым моментом и снимает ряд проблем, существующих при расчетах более традиционными цифровыми инструментами. Самые продвинутые из проектов, экспериментирующих с трансграничными платежами, - канадский проект Jasper, малоазийский проект Ubin, совместный проект Японии и Евросоюза Stella. Создание подобной модели и разработка способов ее применения может стать источником роста в области трансграничных перевозок, логистики, внешней торговли транспортными и ИТ-услугами.

$$
* \quad * \quad *
$$

Таким образом, задачи развития цифровой экономики в Республике Беларусь свя- заны с необходимостью соответствовать мировым тенденциям и не потерять своей конкурентоспособности. Ускорение цифровизации идет стремительными темпами, особенно в последний год, в связи с эпидемией и локдауном. Чтобы занимать здесь позиции полноправного и активного актора, а не аутсайдера, нашей стране следует развивать передовые национальные ИКТ-технологии с критически осмысленным учетом зарубежного опыта, создавать собственные электронные торговые платформы и разветвленную цифровую инфраструктуру, совершенствовать законодательную базу. Объективные возможности и заделы для этого имеются. Их реализацию может обеспечить объединение усилий государства, бизнеса, экспертно-аналитического сообщества.

Особую актуальность эта проблема приобретает и в связи с экономическими особенностями страны, значимостью для стабильной работы белорусской экономики в целом таких сфер, как ИТ и транспортные услуги. Исходя из этого, первоочередное внимание необходимо уделять проблемам цифровизации в следующих областях: развитие платежной системы и финансовых технологий; стимулирование ИТ-услуг и создание благоприятных условий для деятельности парка высоких технологий; совершенствование современных технологий, используемых в логистике и других областях, относящихся к экспорту транспортных услуг. Эти задачи являются первоочередными. От их успешного решения зависит способность белорусской экономики обеспечить приемлемый уровень своих макроэкономических характеристик, сохранить и даже повысить ее конкурентоспособность. Отставание здесь может стать необратимым. Конкретными первоочередными направлениями цифровизации экономики страны следует считать развитие платежного и расчетного пространства, в том числе для транспортных и логистических услуг, систем удаленной идентификации; создание адекватной системы регулирования работы парка высоких технологий; разработку автомобильного интернета и современных стандартов связи, систем электронного документооборота и ряда других цифровых сервисов. 
В целом следует сделать вывод о том, что цифровая экономика имеет огромный потенциал, она будет способствовать необходимой структурной перестройке и не имеет альтернативы для дальнейшего экономического развития Республики Беларусь.

\section{СПИСОК ЛИТЕРАТУРЫ (REFERENCES)}

Елохов А.М., Александрова Т.В. 2019. Подходы к оценке результатов цифровой трансформации экономики России. Учет. Анализ. Аудит. Т. 6. № 5. C. 24-35. [Elokhov A.M., Aleksandrova T.V. 2019. Approaches to Assessing the Results of the Digital Transformation of the Russian Economy. Uchet. Analiz. Audit. Vol. 6. No 5. PP. 24-35. (In Russ.)]
Королева А.А. 2019. Экономические эффекты цифровой логистики. Журнал Белорусского государственного университета. Экономика. № 1. C. 68-76. [Koroleva A.A. 2019. Economic effects of digital logistics. Zhurnal Belorusskogo gosudarstvennogo universiteta. Ekonomika. No 1. PP. 68-76. (In Russ.)]

Сазонов С. 2020. Автомобильный комплекс КНР: императивы инновачионного развития. Москва. ИДВ РАН. [Sazonov S. 2020. Automobile complex of China: Imperatives of innovative development. Moscow: IDV RAN. (In Russ.)]

Столярова Е. 2020. Европейские страны с малой открытой экономикой в международной торговле ИТ-услугами. Банкаўскі веснік. № 10. C. 61-72. [Stolyarova E. 2020. European Countries with Small Open Economies in the International Trade of IT services. Bankauski vesnik. No 10. PP. 61-72. (In Russ.)]

\title{
DIGITAL ECONOMY AND ITS PART IN THE DEVELOPMENT OF FOREIGN TRADE IN THE REPUBLIC OF BELARUS
}

\author{
Anna Galova ${ }^{1}$ \\ Author affiliation: ${ }^{1}$ Belarusian State University (Minsk, Belarus). \\ Corresponding author: Anna Galova (roxan963@mail.ru).
}

ABSTRACT. The article analysis the main directions of digital transformations in Belarusian economy with a special focus on the BOP current account. We identified positions that are to be altered within the context of current digital economy. They are namely payment and settlement services, IT-services, transportservices, logistics. Areas for improving key macroeconomic indicators are considered.

KEYWORDS: digital economy, information and communication technologies, current account, balance of payments, export, import, net balance, IT-services.

JEL-code: E01, O33, P52.

DOI: $10.46782 / 1818-4510-2021-1-130-139$

Received 21.12.2020 